\title{
Biografi på vers
}

Skeden i boktryckaren Anders Björkmans liv

Mång prächtig snilde Wärk af stort astim och wärde

De forne lemnat qwar som warat Konstigt Lärde $[\ldots]^{1}$

SÅ LYDER ETT PAR VERSER ur en gratulationsdikt till Anders Nilsson Björkman, som en grönskande majdag I703 postulerades som boktryckargesäll i Stockholm. Beskrivningar av boktryckarkonstens betydelse och den nya boktryckargesällens utmärkta färdigheter utgör centrala element i persondikter till boktryckare och boktryckargesäller. Ett ofta återkommande tema är också jämförelsen mellan det förgängliga och allt det bestående som boktryckarna med sin flit och skicklighet kan åstadkomma.

Författaren till den postulatdikt som trycktes till Björkmans ära lyfter fram bilder som lämpar sig för situationen: Egyptens pyramider har förfallit, Babels mäktiga murar och torn har upplösts, kungarnas gravar, palats och annan prakt har försvunnit, Alexanders makt och Salomos vishet är inte eviga, järn rostar och hårda diamanter kan krossas. Men himmel och jord består, dygden försvinner inte där den utövas, iver och flit är inte förgäves. Glädjens kransar grönskar år efter år, utan att vika för vinterns kyla eller sommarens hetta. Med dylika ord gjorde den okände författaren även kopplingar till den nyblivne gesällens lagerkrans och namn.

I. Lyck-Önskan framställt/Då Den Äbreborne och Konst-Ehrfarne Anders Nilsson Biörkman/Uppå Postulats Dagen den 29 MajAnno I703. Depositionen undergick/ och ibland Den Edle Boktryckare-Konstens Ledemöter antagen blef. Tienstlig SammanFattat $i$ StoCkholM, [Stockholm]: Tryckt uthi det af Kongl. May:tt privilegerade Goldenaus Tryckeri [1703]. De med antikva tryckta versalerna i texten som i övrigt är i frakturstil tyder på att författarens initialer skulle ha varit S.F.C.M. 
Persondikterna innehade en betydande plats i kulturen under senare delen av I6oo-talet, det vill säga i synnerhet från r67o-talet framåt, och på I70o-talet. De skrevs till bröllop, begravningar och andra betydelsefulla tillfällen. De hörde till programmet på olika tillställningar och de skrevs främst för att läsas upp, men en del blev också tryckta. De bevarade tryckta persondikterna kan öppna dörren till sådant som efterkommande generationer inte känner till om en persons livsskeden. ${ }^{2}$

Huvudpersonen i den här essän är den svenske boktryckaren Anders Nilsson Björkman, född på r66o-talet. I finländsk boktryckarhistoria är han framför allt känd som boktryckare vid Kungliga Akademin i Åbo, men uppgifterna om hans tidigaste skeden har varit ytterst fragmentariska. Jag har noterat att det utöver den ovan presenterade gratulationsdikten även har skrivits andra dikter till Björkman, vilket lett in mig på en upptäcktsfärd i hans livsskeden. Jag har hittat gratulations- och sorgedikter till honom och hans närmaste från en tidsperiod som sträcker sig över ungefär tjugofem år. Postulatsgratulationen är den tidigaste av dem. I den här essän berättar jag om vad jag under färden har hittat i dikter, och delvis även i andra källor.

\section{TRADITIONER}

Inledningsvis är det emellertid på sin plats att redogöra för hur man blev boktryckare på I6oo-talet och under första halvan av I7oo-talet, och för den betydelse som postulatet hade i sammanhanget.

Med boktryckare avsåg man en man som genomgått en mångårig utbildning, som var postulerad gesäll och som ägde ett boktryckeri eller ansvarade för ett tryckeri i en annan persons ägo eller i någon institutions namn.

Vägen till att bli boktryckare inleddes som lärling. Lärlingen bodde hos sin mästare, fick av denne bostad och mat, möjligtvis även kläder om man kommit överens om detta med hans föräldrar. Lärlingstiden fick inte vara kortare än fyra år, och under denna tid var lärlingen

2. För en presentation av genren, se Valborg Lindgärde, Arne Jönsson, Daniel Möller \& Arsenii Vetushko-Kalevich (red.), Att dikta for livet, döden och evigheten. Tillfällesdiktning under tidigmodern tid, Göteborg \& Stockholm: Makadam förlag 2020. 
underordnad mästarens disciplin. När lärlingen hade gett prov på sina färdigheter på ett sätt som tillfredsställde boktryckaren och de anställda på tryckeriet blev han kornut, ${ }^{3}$ ett slags novis. Kornuten hade rätt till lön, till skillnad från en lärling. Han fick emellertid inte på eget initiativ resa eller ta anställning på ett annat tryckeri, och var även i övrigt underställd stränga regler. Om kornuten klarade av sin novistid med heder hade han möjlighet att få fulla gesällrättigheter efter att ha gett ett godkänt prov på sina färdigheter. Efter godkänt prov blev han "verklig" boktryckargesäll ("vercklig konstförvant"), vilket skedde genom en särskild postulatsceremoni som alla medlemmar av Boktryckar-Societeten deltog i. I samband med ceremonin upptogs den postulerade gesällen även som medlem av societeten. ${ }^{4}$

Den postulerade boktryckargesällen var inte längre bunden till sin tidigare arbetsgivare, han var fri att röra sig. Han kunde ge sig av på en gesällvandring från ett tryckeri till ett annat och från land till land - han förväntades rentav utveckla sina färdigheter på detta sätt. Om boktryckargesällen ville säkra möjligheten att bli boktryckare i framtiden gjorde han bäst i att göra en gesällvandring som varade minst ett år. Endast en postulerad gesäll hade rätt att leda ett tryckeri som faktor och att använda titeln boktryckare, i det fall att han övertog ett tryckeri exempelvis genom arv eller giftermål. En postulerad gesälls tjänstetid måste vara överenskommen på förhand. Vanligtvis var tjänstetiden ett halvt år, från mässa till mässa, det vill säga mellan höstens och vårens stora kyrkliga högtider, påsken och Mikaelidagen. Denna kontraktsperiod har kallats "mässa". ${ }^{5}$ I samma betydelse har man även använt uttrycken "mass" och "mass termin".

Boktryckarna bildade inte ett skrå eller gille, men uppenbarligen samlade Boktryckar-Societeten senast från I620-talet boktryckarna

3. På tyska Cornut, Hornträger.

4. Nils Wessel, Svenska typografernas historia. Minnesskrift utgiven med anledning av Svenska typografförbundets zo-års jubileum, Stockholm: Svenska typografförbundet I9I6, s. I7-I9. Mera allmänt om boktryckarnas sedvanerätt i Henrik Schück, "Sedvanerätten inom 1700-talets boktryckerier", Nordisk Tidskrift för Bok- och Biblioteksväsen X, Uppsala: Almqvist \& Wiksell i923, s. 70-7i.

5. Wessel, Svenska typografernas historia, s. I9; Schück, "Sedvanerätten", s. 7I-73. 
och boktryckargesällerna i Sverige. ${ }^{6}$ I praktiken var skillnaden jämfört med hantverkarskråna inte stor. ${ }^{7}$

\section{FRÅN GESÄLL TILL BOKTRYCKARE}

Ordet"dygd" upprepas i dikterna till Anders Björkman, liksom i dikter tillägnade andra boktryckare och boktryckargesäller. Det avsåg inte enbart en moralisk egenskap, utan betydde vid den här tiden exempelvis flit, samvetsgrannhet och yrkesskicklighet. Ett annat återkommande uttryck är "den ädla boktryckare-konsten". Konsten prisas i de mest målande ordalag; man betonar dess koppling till vetenskapen och dess betydelse för att sprida kunskap och civilisation. Det från tyskan lånade uttrycket förekommer också $\mathrm{i}$ ingressen till gratulationsdikten tillägnad Björkman: "och ibland Den Edle Boktryckare-Konstens Ledemöter antagen blef." ${ }^{8}$ De svenska och tyska orden konst och Kunst betyder både skicklighet och konstnärlighet, och i betydelsen skicklighet kan ordet nyanseras i konstnärlig riktning. Boktryckarna och sättarna ville markera en skillnad till hantverkare eller personer som utförde tung kroppslig "trälekonst": deras eget arbete räknades till artes liberales, de fria konsterna.

Gratulationsdikten till Anders Björkman trycktes som patentfolio, det vill säga som ett ettbladstryck på ena sidan av ett ark. Ovanför den luftiga textsatsen syns ett skickligt utfört boktryckarvapen. Högst upp syns färgbollar hållna av en grip, en mytologisk figur med drakhuvud och fågelvingar. På vapenskölden nedanför finns en tvehövdad örn, som i ena klon håller en tenakel, i den andra klon färgbollar, tamponger. ${ }^{9}$

Den finländske bokhistorikern Carl-Rudolf Gardberg lade märke till detta boktryckarvapen i Anders Björkmans postulatsgratulation. På den tiden var det den äldsta kända publikationen i Sverige där vapnet förekom. Eftersom dikten trycktes på Nathanael Goldenaus

6. Jacob Albrecht Flintberg, Borgerlige Förmoner och Skyldigheter, I Stöd af Författningar. Första Delen, Om Minut-Handelen och Handtwerkerierne. Första Afdelningen, Som innefattar Titlarne: Academier, Adel, Allmoge, Bagare, Bleckslagare, Bokbindare, Bokhandlare, Boktryckare, Stockholm I786, s. I07.

7. Wessel, Svenska typografernas historia, s. 2I.

8. Lyck-Önskan framställt.

9. I sättarens tenakel som var fäst i en typkast hölls manuskriptet på lämpligt läsavstånd när texter sattes. Tryckbläck och -färg spreds ut på satsen med färgbollar. 
boktryckeri i Stockholm antog Gardberg att Björkman skulle ha varit i Goldenaus tjänst när han fick gesällvärdighet. ${ }^{10}$ Mina egna efterforskningar i bruket av samma boktryckarvapen leder till en tidpunkt tre år därförinnan. ${ }^{11}$

Pionjären inom svensk boktryckarhistoria, G.E. Klemming, hävdar att Björkman efter postulatet skulle ha blivit faktor på den stockholmske boktryckaren Henrik Keyser III:s boktryckeri, vilket har visat sig vara oriktigt. ${ }^{12}$ Följande uppgift om Björkman är från år 1711. Utifrån bevarade dokument har Gardberg konstaterat att Björkman vid den tiden verkade som faktor på det tryckeri som tillhörde Keyser II:s dödsbo i Stockholm, innan han i slutet av samma år flyttade till Åbo. ${ }^{13}$ Akademiboktryckaren i Åbo, Johan Larsson Wall, hade avlidit I7ı och akademins fäder hade börjat se sig om efter en lämplig efterträdare. De var villiga att välja Anders Björkman till posten. Ett villkor var emellertid att den nye boktryckaren måste sörja för företrädarens anhöriga. Walls änka var Elisabeth Thuronia, vars första make var akademins tidigare boktryckare Peter Hansson (död I679). I det äktenskapet hade dottern Margareta fötts, och när Elisabeth Thuronia ingick nytt äktenskap blev Johan Wall Margareta Hansonias styvfar.

Björkman och akademins fäder kom överens om att Björkman skulle gifta sig med Margareta Hansonia. Björkman anlände till Åbo

Io. Carl-Rudolf Gardberg,"Boktryckarvapnet i äldre svenskt tryck. Några randanteckningar till en postulatsskrift från år I703”, Grafiskt Forum, Svenska boktryckareföreningens meddelanden ıo, Stockholm: Grafiskt forum I947, s. 287-289.

II. Heders-Skrift Och Lyck-Önskan Till Dhe Ehreborne och Konst-Ehrfarne Martin Gottfried Zuzel/ Anders Kjälberg/Lars Guzelius, Jöran Bergstedt/ Hwilke/ sedan de sin Ordinarie Lähre-åhr med behöriga flijt wäl igenom gådt hadel med sedwanlige Ceremonier for Gesäller uti den Edle Booktryckare Konsten gode erkiände och antagne blefwo; Som skedde i Kongl. Residenz Staden Stockholm/ på deras Postulats dag/ den I2. Februarii Anno I70o, [Stockholm: Olof Enaeus I700].

I2. G.E. Klemming \&J.G. Nordin, Svensk boktryckeri-bistoria I483-I883. Med inledande allmän öfversigt, Stockholm: P.A. Norstedt \& Söners förlag I883, s. 227. I verket behandlar Klemming tiden före I80o-talet och Nordin I80o-talet. Boken utgavs I983 som jubileumsutgåva i faksimil med tillägg: G.E. Klemming \& J.G. Nordin, Svensk boktryckeri-historia 1483-I883: med allmän öfversigt, [Bromma]: Mannerheim \& Mannerheim 1983. Se även följande artikel i jubileumsutgåvan: Johan Mannerheim, "Svenska boktryckarlängder I483-1883".

13. Carl-Rudolf Gardberg, Boktrycket i Finland intill freden i Nystad, Helsingfors: [C.-R. Gardberg] I948, s. 243, 368. 
i oktober I7II och bröllopet ägde rum den första maj I7ı2. ${ }^{14}$ Det nyvigda paret fick ta emot en bröllopsgratulation, där texten överst på titelsidan kan betraktas som en inledning:

Kan eij Swänska Gåssar råka

Flickor uthi Swea Land?

Hwij måst' the til Finland tråka/

At här räcka Trohets Hand? ${ }^{15}$

I första strofen av sin bröllopsdikt gör författaren reflektioner av följande art: Vem har inte hört att talrika finländska junkrar har rest till Stockholm för att skaffa sig en hustru, eftersom det i Åbo inte finns någon så förtjusande att hon skulle ha tänt deras kärlekslåga. I dikten "Medh hundra tusend falsar På Kiortel” promenerar fröknarna i Stockholm i sina plisserade kjolar, muffar och skor - söta och städade som putsade fat. Diktaren konstaterar att en sådan fröken kostar pengar och dukater, och lägger därpå följande ord i Björkmans mun:

Then at förwärfwa migh

Måst jagh the böljor bryta/

Som högt uphäfwa sigh

Åth himla fästet skryta;

Jagh menar Ålands haf/

Thet jagh besegla skal/

Jag fruchtar eij för qwaf/

El' stormens gny och knall: ${ }^{16}$

Därefter fortsätter diktaren i tredje person genom att konstatera att Björkman inte härjar som många andra sprättar, som finländska flickor ser ner på och menlösa kvinnor hatar:

I4. Ibid., s. $244-245,248$.

15. J. Sprengberg, Kan eij Swänska Gåssar råka Flickor uthi Swea Land? Hwij måst' the til Finland tråka/ At här räcka Trohets Hand? Frågas och afslites/ Tå Ehreborne och KonstErfarne Herr Andreas Biörckman, Boktryckare wid Kongl. Universitetet i Äbo Uthwalde sigh Ehreborne och Dygdesama Jungf. Margareta Hansonia Til en trogen Wän Och Medh Henne uthi Förnämt samt Hederligit Folcks närwaru den I. Maj Ăhr I7I2. medelst Gudz Ord och the wanlige Kyrkio ceremonier Samman Fogades, [Åbo: H. Chr. Merckell I7ı2].

I6. Ibid. 
Så gaal mång sprätte-höök

Som Finska Flickor ratar/

På Laxen lägger Löök/

Och meenlöst Qwinfolck hatar:

Men wår Herr BJÖRCKMAN så

Eij rasat ända fram/

Ty saden: topp/ kom gå

At Finskan ta i fam.

Han kom/ han såg/ han want

I Finland thet han täncker/

En trohets Ächta Pant/

Til Henne hiertat läncker/ ${ }^{17}$

Dikten, som med verser hopsnickrade på detta tema gratulerade det nyvigda paret, var undertecknad J. Sprengberg. Tryckort nämns inte i publikationen.

Gardberg konstaterade på I940-talet att Sprengberg var "en numera okänd poet”, ${ }^{18}$ men av en gratulationsdikt som är tryckt på J.H. Werners Kungliga boktryckeri framgår att boktryckargesällen Jonas Sprengberg i juni I709 postulerades i Stockholm. ${ }^{19}$ Man känner också till att han var en av Werners gesäller i Stockholm åtminstone år I717. ${ }^{20}$

Men var har Sprengberg skrivit sin bröllopsgratulation och var är den tryckt? Enligt Toini Melanders bibliografi över persondikter har Anders Björkman låtit trycka dikten, den skulle således vara tryckt på Kungliga Akademins boktryckeri i Åbo. ${ }^{21}$ Typografin bekräftar att dikten är tryckt i Åbo, men inte i akademins boktryckeri, utan i

I7. Ibid.

I8. Gardberg, Boktrycket i Finland intill freden i Nystad, s. 245.

19. O. Ringelius, Ingen kan til fyllest låfwa / Ädla Trycketz Himla gåfwa / Som Gud sielf inrättat har / Gör odödlighet förwar. Betrachtat/Då Ehreborne och den Ädle Bok-Tryckare Kånstens Tämmeligen wäl Ehrfarnel Mons. Jonas Sprengberg, Sine Ungdoms Läre-Åhr förwäxlade uti sin Facultets fullkomligare Grad, Hwilken Action tillbörligen Firades / på dess Postulats-Dag I Kongl. Residenz Staden Stockbolm den 8 Junii I709, Stockholm: Kongl. Boktryckeriet I709.

20. Sven Almqvist,"Johan Henrik Werner. Bidrag till en boktryckarbiografi”, Nordisk Tidskrift for Bok- och Biblioteksväsen 53, I966, s. II.

21. Toini Melander, Personskrifter hänförande sig till Finland 1562-I7I3. Bibliografisk förteckning, Helsingin yliopiston kirjaston julkaisuja XXII - Helsingfors universitetsbiblioteks skrifter XXII, Helsinki - Helsingfors I95I-I959, s. 637 (2070). 
det närliggande biskop Johan Gezelius den yngres boktryckeri, vars faktor var Henrich Christopher Merckell. Alla typsnitt i tryckalstret har förekommit i publikationer vid Gezelius boktryckeri vid den här tiden. Det finns uppgifter om personalen vid detta boktryckeri från åren I710 och I7I2, men Sprengbergs namn hittas inte bland dessa. ${ }^{22}$ Motsvarande personuppgifter från akademins boktryckeri från denna tid har inte bevarats. Det är logiskt att anta att den i Åbo tryckta bröllopsgratulationen skulle ha tryckts på brudgummens boktryckeri och att manuskriptet skulle ha sänts till brudgummen, ifall det sänts från annat håll än Åbo. Kanske har Sprengberg emellertid inte velat avslöja sin överraskning och sänt sitt manus till grannboktryckeriet.

Endast ett drygt år efter Anders Björkmans och Margareta Hansonias bröllop, sommaren I7I3, skeppades redskapen och utrustningen från akademins boktryckeri i Åbo, liksom dess personal, över havet till Stockholm. ${ }^{23}$ Åbo ödelades som en följd av att ryska trupper ockuperade Finland under det stora nordiska kriget mellan Sverige och Ryssland; från olika håll i den östra riksdelen hade redan tusentals flyktingar flyttat över till den västra. ${ }^{24}$

Björkman hade gott rykte bland yrkeskollegorna och när han landsteg i Stockholm var boktryckare Johan Henrich Werner snabb med att anställa honom som faktor för Uppsala akademis boktryckeri. Boktryckeriet hade från och med år I7or tillhört Werner, som dock själv bodde och arbetade som kunglig boktryckare i Stockholm, medan akademins boktryckeri verkade under ledning av en faktor. Svenska forskare har emellertid sett det som möjligt att tryckeriet åren I7II-I7I3 var helt utan faktor, eftersom uppgifter om en sådan saknas. Av Uppsala akademis mantalslängd för år I7I4 framgår att det till Björkmans hushåll hörde fyra flyktingar från Åbo, men dessas namn anges inte. ${ }^{25}$

22. Gardberg, Boktrycket $i$ Finland intill freden i Nystad, s. 210.

23. Ibid., s. 250 .

24. Kari Tarkiainen, Moskoviten. Sverige och Ryssland ${ }_{1478}{ }^{-I 72 I}$, Helsingfors: Svenska litteratursällskapet i Finland 20I7, s. 334-335.

25. Samuel E. Bring, Boktryckerierna i Uppsala. Band II: $I 70 I-I 8 r o$, Uppsala: Almqvist \& Wiksells Boktryckeri AB I964, s. 38; Mantalslängd på Academiens Stat och Personal, E III.I4, Landsarkivet i Uppsala. 


\section{Hustruns DÖD}

År 1718 blev Anders Björkman änkling. Till Margareta Hansonias minne trycktes tre begravningsdikter, skrivna av en professor och två studenter som var verksamma vid Uppsala akademi.

Dikten Ehreminne, som är skriven av astronomen Nicolaus (Nils) Celsius, beskriver den avlidnas goda egenskaper och de änglaröster, det harpspel och den sång som väntade henne i himlen - men också de anhörigas och vännernas sorg. ${ }^{26}$ Det är fråga om en konventionell begravningsdikt, som är tryckt i den pråligaste storleken, patentfolio. Detta kan tolkas som en särskild hedersbetygelse för både den avlidna och hennes make, Anders Björkman. Begravningsdikter i patentfolio över boktryckare och deras anhöriga var mycket sällsynta under första hälften av I70o-talet. Pelarna som reser sig på bägge sidor av texten var tryckta med två träsnitt, som hade varit i användning redan i akademins boktryckeri i Åbo. Det är bara ett av flera exempel på att all utrustning som hörde till boktryckeriet inte låg nerpackad $\mathrm{i}$ förvaringslådor i väntan på att återbördas till sin gamla plats, som till exempel Gardberg har antagit. ${ }^{27}$

Av de två övriga dikterna som tillägnades Margareta Hansonias minne, var den ena skriven av Jonas Tidholm, som studerade vid Uppsala akademi på 1710-talet. Hans dikt är skriven i form av den avlidnas egna avskedsord - hon tackar för allt gott som kommit henne till del i livet. ${ }^{28}$ Tidholms namn förekommer på den fyrsidiga publikationens titelsida, men under den sista strofen på sista sidan hittas en annan persons namn:

26. N. Celsius, Ehreminne Och Ytterste Tienst Wisar Då Den Ehreborne och mycket Dygderijke Matronan, Hustru Margareta Hansonia Efter en hastig utstånden sjukdom/ doch gudelig beredelse ifrån denne usle wärlden skildes den 28 Septemb. och des andelöse lekamen sedermera i förnämt och hedersamt Lijkföljes närwaru jordsattes i Upsala Domkyrkogård den 3 Octob. åhr I7I8, Uppsala: J.H. Werner, Kongl. Boktryckare I7I8.

27. Carl-Rudolf Gardberg, Boktrycket i Finland 2. Från freden i Nystad till Åbo brand, Helsingfors: Helsingfors Grafiska klubb i957, s. I.

28. Jonas Tidholm, Ähro-Minne Öfwer Then i lifstiden Ähreborna och Dygdälskande Matronan Hust. Margaretha Hansonia, Boktryckarens Herr Anders Björkmans Kärälskeliga Maka/ Hwilcken saligt afled den 28 Septemb. klockan 11 om natten/ och den 3 October til sitt Lägerställe beledsagades, Uppsala: J. Henr. Werner, Kongl. Boktryckare I7I8. 
Thet är wäl sant I war min Mor/men ei den Moder/

Som mig til wärlden födt/doch war i mig så goder/

At man kan näpligt tro/ Er like finnas lär;

Som så ens annars kan/som sina hålla kär.

Haf therför ewig tack/ min Morkär för then möda/

Som I för mig ha haft/ med lärdom/ kläder/ föda/

Ei skal iag glömma Er/ då länge jag är här.

Far wäl min Mamma kär/ jag Er i minnet bär.

Andreas A. Biörkman. ${ }^{29}$

Detta torde vara den första uppgiften som bevarats för eftervärlden om att Anders Nilsson Björkman hade en son och att äktenskapet med Margareta Hansonia inte var hans första. ${ }^{30}$ Det var denna överraskande upptäckt som fick mig att gräva i gamla dokument, vilket resulterade $\mathrm{i}$ att jag hittade ny information om Anders Björkman och hans skeden.

Det visade sig att Björkman arbetade på det boktryckeri som tillhörde Henrik Keyser II:s dödsbo när han postulerades till gesäll år I703. Keyser II hade avlidit år I699 och hans änka Catharina Höök drev verksamheten. Catharina Höök och Björkman hade råkat i gräl över några betalningar från åren $\mathrm{I}_{703} \mathrm{och} \mathrm{I704}$, och det tog flera år att reda ut saken. Detta framgår av en supplik som Boktryckar-Societeten i december I708 hade riktat till kanslikollegiet i Stockholm till Björkmans försvar. Orsaken till meningsskiljaktigheterna var fordringar som Catharina Höök hade på Björkman, från en tidsperiod som sträckte sig mellan den 27 september I703 och den 8 juli I704. Enligt Björkman var fordringen grundlös:

En sådan oriktig och obillig Räkning fick iag af Mad. Cath. Höök i ställe för min då innestånda lön, lijka som widh Mass Terminen I696 och blef där medh som stor obillig afwijst, betyger Andreas Biörkman. ${ }^{31}$

29. Ibid.

30. Den unge Björkman kan inte ha fötts i ett utomäktenskapligt förhållande. Han blev senare boktryckargesäll, och ett av villkoren för att antas som lärling var att pojken var född inom äktenskapet, ”född i äkta säng”. Wessel, Svenska typografernas bistoria, s. I8.

3I. Inkomna skrivelser från boktryckare, E XII, Kanslikollegiets arkiv, Riksarkivet, Stockholm. 
Av Björkmans svar går det således att sluta sig till att han arbetat på Keysers boktryckeri redan år I696, när Keyser II ännu levde. Att han anser att han då borde ha fått lön tyder på att han hade lärlingstiden bakom sig, det vill säga att han vid den tiden var kornut.

Catharina Hööks skrivelse innehåller också uppgifter om att Björkman hade stannat hemma i två veckor medan hans hustru låg i barnsäng. Dessa veckor har daterats till försommaren I704. Barnet hade därmed fötts cirka ett år efter Björkmans postulat, när han blev erkänd som gesäll.

$\mathrm{Nu}$ sörjde barnet, en cirka fjortonårig pojke, sin styvmor.

\section{ÄGARE TILL ETT BOKTRYCKERI}

Ett par år efter Margareta Hansonias död flyttade Björkman från Uppsala till Stockholm och ingick äktenskap med Sara von der Holtz, änka efter boktryckaren Michael Laurelius. På så sätt blev han år I720 ny ägare till Laurelius boktryckeri. ${ }^{32}$ Klemming konstaterar att boktryckeriet efter Laurelius död övergick till hans änka, men han kan inte namnge henne. Att boktryckeriet övergick från en "namnlös" änka till Anders Björkman har gett upphov till det felaktiga antagandet att änkan skulle ha sålt sitt boktryckeri till Björkman. ${ }^{33}$ Bröllopsgratulationen till Björkman och Sara von der Holtz visar emellertid att skiftet skedde på ett högst traditionellt sätt. Det säkraste sättet att bli ägare till ett boktryckeri var att gifta sig med boktryckarens änka. Bröllopsdikten förmedlar en bild av en sympatisk kvinna som inte

32. Enligt Klemmings felaktiga uppgifter skulle Sara von der Holtz ha varit gift med Nathanael Goldenau (d. I705/1706), därefter med Julius Georg Matthiæ (d. I716) och sedan med Johann Laurentz Horrn. Klemming \& Nordin, Svensk boktryckeri-bistoria (1883), s. 223, 226-227. Dessa felaktiga uppgifter upprepas i senare litteratur. Av flera bröllops- och begravningsdikter framgår det klart att Goldenaus fru och änka var Maria Mattheis och att Sara von der Holtz vid olika tidpunkter var gift med boktryckarna Michael Laurelius och Anders Björkman, samt efter den senares död Petter Jöransson Nyström.

33. Så har bland andra Jan Drees förstått saken. Se Jan Drees, Deutschsprachige Gelegenheitsdichtung in Stockholm und Uppsala zwischen I6r3 und I719. Bibliographie der Drucke nebst einem Inventar der in ihnen verwendeten dekorativen Druckstöcke, Acta Bibliothecæ Stockholmiensis LVI, Stockholm: Kungliga biblioteket 1995, s. 345 . 
jamsar i onödan..$^{34}$ Författaren, signaturen Skyldigast Redebogen, har högst troligt varit en av Laurelius gesäller.

Efter att freden i Nystad I72I avslutade stora nordiska kriget, återupptogs verksamheten vid Kungliga Akademins boktryckeri i Åbo år I723. Björkman lät sig inte lockas tillbaka till Åbo, men hans ställning som akademins boktryckare upphävdes så vitt vi vet aldrig. ${ }^{35}$ I nästan alla publikationer tryckta i Stockholm har han använt titeln Akademiboktryckare i Åbo, vilket stundom har orsakat förvirring då man har tolkat uppgifterna om tryckort.

\section{FADERNS FOTSPÅ}

Anders Björkman den yngre fortsatte i faderns fotspår. Han postulerades till gesäll år 1725 och gratulerades av de anställda på Björkmans boktryckeri med en dikt på tyska. ${ }^{36} \mathrm{I}$ denna lyckades man kombinera boktryckarkonstens betydelse för vetenskapen, växtligheten som spirar i maj, bekransningen av den nye gesällen och lövhyddohögtiden. Utifrån hans namn skapade man en ny liknelse: Björkmans färdigheter hade utvecklats och han hade blivit förtjänt av så mycket respekt och beröm, att hans krona i"Sveriges Libanon" vuxit sig lika hög som cedrarnas kronor. Libanons ståtligt cederskogsklädda bergskammar finns beskrivna i ett par böcker i Gamla Testamentet, och läsare som var förtrogna med Bibeln förstod vad liknelsen syftade på. Den nypostulerade gesällens

34. Då Boktryckaren/Ehreborne och Högwälachtade Herren/ Herr Anders Björkman, Samt Ehreborna och Dygdesamma Matronan, Hustru Sara von der Holtz, Ingingo et Christeligit ächta förbund/ som skedde i Stockholm den 24 Julii I720, i Förnämt folks närwaro/ yttrar sig i största bastighet/ enfaldigt/ dåck wälment/ den som til de hederwärde Contrahenternas tienst altid är/ och skal finnas Skyldigast Redebogen, [Stockholm: Anders Björkman I720]. Signaturens inledande bokstäver har accentuerats genom att sättas med antikva, även om orden i övrigt har satts med fraktur. Troligtvis uttrycker de författarens initialer S.R.

35. Gardberg, Boktrycket $i$ Finland 2, s. 5 .

36. Das Im Seegen Mit Ehr und Freude Erhaltene und vollzogene Postulat Dess WoblEhren-Besten, Vorachtbaren und Kunst-geübten Herrn Andreas Biörkmans Der Edlen Typographice Studiosi, Und Buchdruckerey Kunstpreislichen Genoßens, In der Köningl. Residenz- und Haupt-Stadt Stockholm, am 7 Tage deß Monaths Maji, MDCCXXV. Mit wohlmeynende, Glücks-Wundsche Zu vielfältigem Auffnehmen geehret Von Der Biörkmannischen Druckerey Sämptlichen Kunst-Genoßen, Stockholm: Anders N. Björkmans boktryckeri 1725 . 
far tackades bland annat för att han tidigt hade erbjudit sonen möjlighet att bekanta sig med grunderna även i andra språk än svenskan. Gratulanterna visste också att den nye gesällen ämnade ge sig iväg på resa, på en gesällvandring, och önskade honom mångahanda gynnsamma erfarenheter i främmande länder. Samtidigt hoppades de att han när han återvände skulle finna fadern och modern vid god hälsa.

Vid avresan träffades den unge Anders och hans föräldrar för sista gången.

\section{Minnesdikterna Ber ̈̈tTAR}

Boktryckare Anders Nilsson Björkman dog år I728 lite över 6o år gammal - "Efter några och Sextijo Åhrs ärbare Wandel" - kan vi läsa på titelbladet till en minnesdikt skriven av Gudmund Humbla Ericksson, som verkade som präst i Strängnäs. ${ }^{37}$ I dikten förekommer inga uppgifter om Björkmans födelseår, och jag har heller inte hittat det i andra sammanhang. Den innehåller emellertid andra uppgifter om Björkman som jag inte har stött på i forskningslitteraturen. Humbla berättar att Björkman föddes på Tynnelsön i Mälaren och att hans föräldrar sände honom till Strängnäs för skolgång. Någon gång under skoltiden blev emellertid "Honom Faders Hielp, och Moders stöd beröfwat", vilket tyder på att han av en eller annan orsak förlorade föräldrarnas stöd. Detta kan tolkas som att skolgången avbröts och att Björkman slutligen sökte sig i boktryckarlära.

I förteckningarna över elever i Strängnäs skola har jag hittat endast ett namn som kunde hänvisa till Björkman: Andreas Nicolai, det vill säga Anders Nilsson, som inledde sin skolgång år I672. ${ }^{38} \mathrm{Om}$ Björkman har börjat som boktryckarlärling i Strängnäs, måste det ha skett på Zacharias Asps boktryckeri. Asp sålde sitt tryckeri till Keyser II i

37. Gudmund Humbla Ericksson, The Trognas Lidande Säsom En Beseglad och Öpen Book, Utaf Uppenb. 5. Cap. Wid warande dödelige Frånfälle, Förestälte, Enär För detta Kongl. Academia Boktryckaren uti Åbo, Ehreborne och Högachtade Herren, Herr Anders Biörkman/ Efter några och Sextijo Åhrs ärbare Wandel, I Herranom stilla och saligen afsomnade den I2 Julii; Hwilken sedan til sin kropps öfwerlefwor i the Blomster-Gröna Jordenes skiöte Christ-Hederligen nederlades i S:t Clare Kyrckia den ${ }_{4} 4$ Ejusdem Åhr I728, Stockholm: Tryckt med Sal. Herr Biörkmans Bokstäfwer I728.

38. Harald Petersson, Matricula Regii Collegii Strengnensis I: 1628-1699, Strängnäs: Akt. Bol. Strengnäs Tidnings tryckeri I947, s. 35. 
Stockholm, uppskattningsvis I69o. ${ }^{39}$ Möjligtvis är detta den väg som ledde Björkman till Keysers boktryckeri.

Även boktryckargesällen Johan Anders Schultz, som enligt sina egna ord var gammal vän till den saligt avlidna, berättar om Anders Björkman i sin minnesdikt Then sjelf har tryckt mång wacker Skrift / Med Skrifft bör hedras på sin Grift. ${ }^{40} \mathrm{Han}$ prisar Björkman som en rejäl karl och berättar att han hade lärt sig sitt yrke både i hemlandet och utomlands: "Så inn- som utom Landz först Konsten flitigt lärdt / Sen uti stillhet sig med Tryckeriet närdt."

I vilket skede har Björkman varit utomlands, var och när har han lärt sig tyska, ett språk som verkar ha haft en framträdande plats i hans liv? Åtminstone åkte han inte iväg på gesällvandring strax efter postulatet, han var ju då i tjänst hos Keysers änka och väntade familjetillökning. Och när förhandlingarna om positionen som boktryckare vid Kungliga Akademin i Åbo pågick i början av år I III var Björkman faktor på Keysers arvingars boktryckeri. ${ }^{41}$ Troligtvis har han gjort den sedvanliga gesällvandringen mellan åren 1705 och i710.

Schultz skrev också om den tunga sorg som fick Björkmans hjärta att blöda, en sorg som kanske också bidrog till hans död. Hans ende son Anders, som år 1725 åkt till Tyskland, hade dött i Leipzig.

Till Björkman den äldres minne utkom också en begravningsdikt tryckt som vacker patentfolio, sonetten Die letzte Pficht und Schuldig-

39. Klemming \& Nordin, Svensk boktryckeri-bistoria $1483-1883$, s. 227.

40. Joh. Andreas Schultz, Then sielf har tryckt mång wacker Skrift/ Med Skrifft bör hedras på sin Grifft. Ihogkommit Då För thetta Boktryckaren wid Abo Akademie, Then Ehreborne och Högwälachtade Herren/Herr Andreas Biörckman, Effter En i Herranom förd stilla och Dugelig wandel, samt redelig och ährbar Omgiängelse bland menniskior thetta timeliga i thet ewiga forbytt then I2 Julii, År $1728 /$ Och Then therpa foljande samma åhr uti förnämt och hederligt Folcks närwaro med Christ-loflige Ceremonier d. I4. Julii til sin Graf och bwilorum beledsagades uti S. Clara Kyrckio; Och framtedt Af en then Sal. dödas gamla wän Joh. Andreas Schultz, Stockholm: Tryckt hos Johann Laur. Horrn. Kongl. Antiquitæts Archivi Boktryckare 1728.

4I. Gardberg, Boktrycket i Finland intill freden i Nystad, s. 243. Man har antagit att Johan Emanuel Balduin var faktor för Keyser II:s arvingar från och med I699, kanske ända till I7I2. Se Mannerheim, "Svenska boktryckarlängder I483-I883", s. 95. Björkman har således blivit faktor i Balduins ställe redan tidigare. 
keit. ${ }^{42}$ Den börjar med följande rader:"Läst Du/ mein Herr PATRON, die Presse stille stehen / Der Du so manches Buch gegeben an den Tag?" ("Tillåter du, min patron, att tryckmaskinen stannar / du, som låtit så många böcker se dagens ljus?”). Den okände författaren har varit en av Björkmans gesäller.

I begravningsdikterna tryckta till Björkmans minne nämns i samband med hans namn också hans ställning som boktryckare vid akademin i Åbo, i formen "Kongl. Academiæ Boktryckiaren i Åbo" eller "För detta Kongl. Academiæ Boktryckiaren i Åbo". Även om hans verksamhet i Åbo vid det här laget låg I5 år tillbaka i tiden, hedrades han ända till slutet av sitt liv med denna ansedda titel.

Persondikten är som en tablå, vars gestalter vi ser i en frusen position. Persondikterna till Anders Björkman och hans närstående tillkom under en tjugofemårsperiod, men det som de förmedlar kan sammanfogas till en fragmentarisk berättelse som sträcker sig över en längre tid. Berättelsen tar sin början i tidig barndom, skildrar en bekransad boktryckargesäll, en boktryckare i Sveriges universitetsstäder och Stockholm, äktenskapen han ingick, de närståendes död - och slutligen hans egen. Dessa dikter rymmer glädje och sorg, komik och tragedi, överdrifter och värme. Det är som om de bildar en skuggföreställning i dämpad belysning och med rum för tolkning.

Översättning till svenska av Elisabeth Stubb

42. Die letzte Pficht und Schuldigkeit/Wolte Bey dem Grabe Des Wohl-Edlen und Wohlfürnehmen Herrn/ Herrn Andrea Björkmans, Königl. Academie-Buchdruckers in Abol Welcher nach ausgestandener Kranckheit den I2. Julii seinen Christlich geführten Wandel beschloß/ und seine Seele seinem Heyland JESU CHristo wieder überantwortetel Und darauf den I4. Jul. a. c. zu St. Clara in seine Ruhe-Cammer niedergesetzet wurde, Erweisen, Jn Christlicher Bescheidenheit, Stockholm I728. 